\title{
Surveillance of tuberculosis in Europe
}

\author{
H.L. Rieder*, J.M. Watson**, M.C. Raviglione+, M. Forssbohm++, \\ G.B. Migliori\#, V. Schwoebel\#\#, A.G. Leitch $¥$, J-P. Zellweger $¥$
}

\author{
Recommendations of a Working Group of the World Health Organization (WHO) and \\ the European Region of the International Union Against Tuberculosis and Lung Disease (IUATLD) \\ for uniform reporting on tuberculosis cases
}

Surveillance of tuberculosis in Europe. H.L. Rieder, J.M. Watson, M.C. Raviglione, M. Forssbohm, G.B. Migliori, V. Schwoebel, A.G. Leitch, J-P. Zellweger. Recommendations of a Working Group of the World Health Organization (WHO) and the European Region of the International Union Against Tuberculosis and Lung Disease (IUATLD) for uniform reporting on tuberculosis cases. CERS Journals Ltd 1996.

ABSTRACT: Consensus-based recommendations have been developed by a Working Group of the World Health Organization (WHO) and the European Region of the International Union Against Tuberculosis and Lung Disease (IUATLD) on uniform reporting of tuberculosis surveillance data in the countries of Europe.

A uniform case definition and a minimum set of variables for reporting on each case have been agreed which, when collated on a national basis, will allow comparison of the epidemiology of tuberculosis in different European countries.

The Working Group recommends that the case definition includes "definite" cases, where the diagnosis has been confirmed by culture (or supported by microscopy findings in countries where diagnostic culture facilities are not available), and "other than definite cases" based on a clinical diagnosis of tuberculosis combined with the intention to treat with a full course of antituberculosis therapy. Both "definite" and "other than definite" cases should be notified by physicians and, in addition, laboratories should be required to report "definite" cases.

The minimum set of variables to be collected on each case of tuberculosis should include: date of starting treatment, place of residence, date of birth, gender, and country of origin, to characterize the patient. Recommended disease-specific variables include: site of disease, bacteriological status (microscopy and culture), and history of previous antituberculosis chemotherapy.

The minimum set of variables should be collated on all patients and should be as complete as possible. Additional variables may be collected for individual, local or national purposes, but, in general, completeness of reporting on cases is likely to be better if the information requested is kept to a minimum.

Timely reporting of cases is essential for appropriate public health action. Cases should be reported to the health authority at the local and/or regional level within 1 week of starting treatment. Individual-case based information should be reported to the national level by the local or regional level. Feedback to reporters is essential. At the national level, preliminary quarterly reports should be produced and final reports should be published annually.

Eur Respir J., 1996, 9, 1097-1104.
*International Union Against Tuberculosis and Lung Disease, Paris, France. ***ublic Health Laboratory Service Communicable Disease Surveillance Centre, London, UK. +Tuberculosis Programme, World Health Organization, Geneva, Switzerland. ${ }^{++}$German Central Committee against Tuberculosis (DZK)/Public Health Office, Wiesbaden, Germany. "Fondazione Salvatore Maugeri, Clinica del Lavoro e della Riabilitazione, Care and Research Institute, Tradate, Italy. \#European Centre for the Epidemiological Monitoring of AIDS, Saint-Maurice, France. tal, Royal Victoria Chest Clinic and Tuberculosis Service, Edinburgh, UK. $¥$ Swiss Association against Tuberculosis, Berne, Switzerland.

Correspondence: H.L. Rieder Tuberculosis Section of IUALTD

Jetzikofenstr. 12

3038 Kirchlindach

Switzerland

Reprint requests: Global Tuberculosis Programme, World Health Organization, 1211 Geneva 27, Switzerland, or International Union Against Tuberculosis and Lung Disease, 68, Boulevard saint-Michel, 75006 Paris, France.

Keywords: Europe, surveillance, tuberculosis

Received: October 91995

Accepted for publication December 201995
Public health surveillance has been defined as the ongoing systematic collection, analysis, and interpretation of outcome-specific data, closely integrated with the timely dissemination of these data to those responsible for preventing and controlling disease or injury [1]. The epidemiology of tuberculosis may be monitored by surveillance of incident cases, prevalent cases, risk of infection with Mycobacterium tuberculosis complex (derived from tuberculin skin test prevalence surveys), and deaths from tuberculosis. In practice, the most readily accessible and informative indicator of tuberculosis morbidity is the number of incident cases.
This report is a direct extension of recommendations made by a European working group in 1990 [2]. Data on tuberculosis notifications in western and eastern Europe have recently been analysed [3,4]. During the compilation of data, it was noted that differences in case definitions between various countries made comparison difficult. Similar difficulties with case definitions hampered further analysis of tuberculosis control in relation to international migration in Europe [5]. That analysis recommended common principles for surveillance of tuberculosis in European countries and agreed a minimum data set [5]. This paper delineates these common principles and specifies 
the variables in the common data set, which will allow European countries to collect comparable data as recommended elsewhere [6], and also to respond to matters of public concern. Although the paper emphasizes the rationale for collecting only a small number of variables relating to each case of tuberculosis, the system could easily be expanded to gather more detailed information, customized to the needs of individual countries.

It should be emphasized that, whilst surveillance is an integral part of monitoring the effectiveness of interventions, this paper does not address monitoring of treatment programme performance.

\section{Aims and objectives of surveillance}

Surveillance of tuberculosis should serve two major purposes. It should enable an accurate picture to be obtained of the course of the tuberculosis epidemic in a community over time and permit timely intervention if the trend observed deviates from what is expected. Secondly, the characterization of cases should be sufficiently detailed to allow, in conjunction with appropriate population figures, the identification of groups in the community at particularly high risk of tuberculosis, so that interventions and resources can be targeted more efficiently.

Tuberculosis surveillance has local, national and international functions. At the local level it is important so that the public health authorities can ensure that: 1) appropriate treatment services are offered to the individual; 2) contact tracing is carried out; 3) local outbreaks are recognized; and 4) the local epidemiology is monitored.

At the national level the emphasis is different. Surveillance enables the public health authority to: 1) monitor the epidemiology of the disease in the country, including trends over time, and variations in incidence in population subgroups; 2) take the first step in the process of monitoring the success of the national treatment programme for tuberculosis; and 3) monitor the effectiveness of specific tuberculosis control and prevention measures.

At the international level, the objectives are to monitor the epidemiology of the disease in the entire European region, including trends over time and intercountry comparisons, and to identify high incidence population groups which may be common to several countries with a view to co-ordinating efforts in tuberculosis control at an international level.

The principles guiding tuberculosis surveillance programmes must include: 1) that information on cases should be collected locally; 2) that a range of information sources should be utilized so as to maximize the ascertainment of cases, e.g. clinicians, laboratories, pharmacies, social security organisations, etc., provided that linking is possible to avoid double counting; 3 ) that a minimum data set for collection of information on cases should be utilized; 4) that standard case definitions should be used for the purposes of reporting to the national centre; 5) that data on individual cases should be collated nationally to permit detailed analyses of reported cases and, where appropriate, linking of case registers to other appropriate disease registers; and 6) patient confidentiality should be strictly maintained.
In this document, data collected locally are discussed only in relation to national data collection. In particular, items which might be relevant for management of individual patients or for contact tracing are excluded from discussion if they have no potential bearing on national or European-wide public health policy. Such omissions should not be interpreted as representing the Working Group's position as to their necessity, but rather as an acceptance of widely divergent needs at local level beyond the scope of this paper.

\section{Review of current surveillance systems in Europe}

The Working Group reviewed current activities in tuberculosis surveillance in European countries. The results of this survey, summarized in table 1 , show that an overwhelming majority of countries base their reporting system on a case definition of tuberculosis. In only a few countries are cases reported anonymously, and reporting is almost universally mandatory, at least by physicians, but often by both physicians and laboratories. Age, gender, site of disease, and bacteriological status are almost uniformly required reporting variables on cases, and many countries additionally request information on country of birth and history of previous treatment. With few, but important, exceptions, the information collected locally or regionally, is also collated nationally.

\section{Case definition}

To allow comparability both within and between countries, a uniform definition of a notifiable case of tuberculosis is essential. Different countries require different categories of disease to be reported. The lowest common denominator recommended for uniform reporting in countries where level II laboratories [7] are routinely available is a case of tuberculosis in which M. tuberculosis complex has been identified by culture.

A "definite" case of tuberculosis is a case with culture confirmed disease due to M. tuberculosis complex (in countries in which level II laboratories are not routinely available or where routine culturing of specimens from all cases cannot be afforded or expected, a patient with sputum smear examinations positive for acid-fast bacilli (AFB) is also considered to be a "definite" case).

Reporting is also required of "other than definite" cases, which meet both of the following conditions: 1) a clinician's judgement that the patient's clinical and/ or radiological signs and/or symptoms are compatible with tuberculosis; and 2) a clinician's decision to treat the patient with a full course of antituberculosis therapy.

"Definite" and "other than definite" cases should be reported separately to permit an international comparison of definite cases and their proportion among all cases.

"Definite" (and, where applicable, "other than definite") cases of pulmonary tuberculosis should be divided into smear-positive and smear-negative cases based on direct microscopic smear examination of spontaneously produced or induced sputum. Cases which are positive on microscopy of bronchoalveolar or gastric lavage material only should not be considered to be sputum 
Table 1. - Surveillance of tuberculosis in Europe: results of a survey in Europe on reporting of cases and routinely collected variables

Reporting

Country Case Mand Nom MD Lab Date Age Sex Country Site Bact Hist Loc Reg Nat def.

\begin{tabular}{|c|c|c|c|c|c|c|c|c|c|c|c|c|c|c|}
\hline Albania & $\bullet$ & - & - & $\bullet$ & O & - & $\bullet$ & $\bullet$ & $O$ & - & - & O & $O$ & - \\
\hline Andorra & - & - & - & • & • & - & $\bullet$ & $\bullet$ & - & • & - & O & O & O \\
\hline Armenia & $\bullet$ & $\square$ & - & $\square$ & $\square$ & ○ & ○ & $\bullet$ & ○ & - & ○ & - & - & ○ \\
\hline Azerbaijan & • & O & • & • & $\bullet$ & - & 0 & - & - & - & - & - & $\bullet$ & - \\
\hline Austria & O & - & - & • & O & - & • & $\bullet$ & • & - & • & O & O & O \\
\hline Belarus & 0 & $\square$ & - & - & $\bullet$ & ○ & ○ & - & 0 & - & - & - & - & - \\
\hline Belgium & $\bullet$ & $\bullet$ & $\bullet$ & $\bullet$ & $\bullet$ & $\bullet$ & $\bullet$ & $\bullet$ & O & - & ○ & $\bullet$ & $\bullet$ & - \\
\hline Bosnia/ . & $\bullet$ & $\bullet$ & ○ & ○ & O & $\bullet$ & $\bullet$ & $\bullet$ & • & $\bullet$ & • & $\bullet$ & O & - \\
\hline Herzegovina & & & & & & & & & & & & & & \\
\hline Bulgaria & - & $\bullet$ & ○ & $\bullet$ & $\bullet$ & $\bullet$ & $\bullet$ & $\bullet$ & - & $\bullet$ & $\bullet$ & $\bullet$ & O & - \\
\hline Croatia & - & - & $\bullet$ & $\bullet$ & O & $\bullet$ & - & $\bullet$ & O & - & - & O & $\bullet$ & - \\
\hline Czech Republic & $\bullet$ & $\bullet$ & - & $\bullet$ & $\bullet$ & $\bullet$ & $\bullet$ & $\bullet$ & O & $\bullet$ & $\bullet$ & O & O & O \\
\hline Denmark & $\bullet$ & $\bullet$ & - & $\bullet$ & $\bullet$ & - & - & $\bullet$ & $\bigcirc$ & $\bullet$ & - & - & $\bullet$ & ○ \\
\hline Estonia & $\bullet$ & $\bullet$ & - & $\bullet$ & $\bullet$ & $\bullet$ & • & $\bullet$ & • & • & $\bullet$ & - & O & - \\
\hline Finland & $\bullet$ & • & • & $\bullet$ & $\bullet$ & • & • & $\bullet$ & • & • & - & • & O & - \\
\hline France & - & - & O & $\bullet$ & O & - & - & $\bullet$ & 0 & - & - & - & • & O \\
\hline Georgia & O & $\bullet$ & $\bullet$ & $\bullet$ & $\bullet$ & $\bullet$ & $\bullet$ & $\bullet$ & $\bullet$ & $\bullet$ & - & $\bullet$ & $\bullet$ & $\bullet$ \\
\hline Germany & - & - & - & 0 & • & - & 0 & $\bullet$ & O & - & - & O & • & - \\
\hline Greece & $\bullet$ & $\bullet$ & • & $\bullet$ & O & $\bullet$ & $\bullet$ & $\bullet$ & O & $\bullet$ & - & O & $\bullet$ & ○ \\
\hline Hungary & $\bullet$ & $\bullet$ & • & $\bullet$ & $\bullet$ & $\bullet$ & • & $\bullet$ & O & - & • & - & $\bullet$ & - \\
\hline Iceland & 0 & - & - & 0 & - & • & - & - & O & - & - & - & O & O \\
\hline Ireland & $\bullet$ & $\bullet$ & - & $\bullet$ & O & $\bullet$ & $\bullet$ & $\bullet$ & O & $\bullet$ & - & $\bullet$ & $\bullet$ & O \\
\hline Israel & $\bullet$ & $\bullet$ & ○ & $\bullet$ & $\bullet$ & $\bullet$ & $\bullet$ & $\bullet$ & $\bullet$ & $\bullet$ & $\bullet$ & $\bullet$ & $\bullet$ & $\bullet$ \\
\hline Italy & $\bullet$ & - & - & $\bullet$ & O & $\bullet$ & $\bullet$ & $\bullet$ & O & $\bullet$ & - & O & $\bullet$ & - \\
\hline Kazakhstan & $\bullet$ & $\bullet$ & $\square$ & O & O & $\bullet$ & $\bullet$ & $\bullet$ & • & $\bullet$ & • & • & $\bullet$ & - \\
\hline Kyrgyzstan & $\bullet$ & $\bullet$ & $\square$ & $\bullet$ & $\bullet$ & $\bullet$ & $\bullet$ & $\bullet$ & - & $\bullet$ & - & O & $\bullet$ & - \\
\hline Latvia & $\bullet$ & $\bullet$ & ○ & $\bullet$ & - & $\bullet$ & $\bullet$ & $\bullet$ & O & $\bullet$ & - & ○ & $\bullet$ & - \\
\hline Lithuania & 0 & - & - & 0 & • & - & - & $\bullet$ & - & - & - & - & O & - \\
\hline Luxembourg & • & $\bullet$ & $\bullet$ & $\bullet$ & $\bullet$ & $\bullet$ & $\bullet$ & $\bullet$ & O & $\bullet$ & ○ & O & O & O \\
\hline Malta & $\bullet$ & $\bullet$ & • & $\bullet$ & $\bullet$ & $\bullet$ & $\bullet$ & $\bullet$ & $\bullet$ & $\bullet$ & $\bullet$ & • & O & O \\
\hline Moldova & $\bullet$ & ○ & - & $\bullet$ & • & $\bullet$ & $\bullet$ & $\bullet$ & ○ & $\bullet$ & - & ○ & O & ○ \\
\hline The Netherlands & $\bullet$ & - & - & $\bullet$ & O & - & $\bullet$ & $\bullet$ & - & - & - & - & $\bullet$ & O \\
\hline Norway & $\bullet$ & - & ○ & $\bullet$ & $\bullet$ & - & $\bullet$ & $\bullet$ & ○ & - & - & ○ & $\bullet$ & O \\
\hline Poland & $\bullet$ & $\bullet$ & $\bullet$ & $\bullet$ & $\bullet$ & $\bullet$ & $\bullet$ & $\bullet$ & $\bullet$ & $\bullet$ & $\bullet$ & $\bullet$ & $\bullet$ & $\bullet$ \\
\hline Portugal & $\bullet$ & $\bullet$ & - & $\bullet$ & O & $\bullet$ & $\bullet$ & $\bullet$ & O & $\bullet$ & $\bullet$ & $\bullet$ & $\bullet$ & $\bullet$ \\
\hline Romania & $\bullet$ & $\bullet$ & $\bullet$ & $\bullet$ & $\bullet$ & $\bullet$ & $\bullet$ & $\bullet$ & O & - & - & $\bullet$ & $\bullet$ & O \\
\hline Russia & $\bullet$ & - & - & $\bullet$ & $O$ & $\bullet$ & - & $\bullet$ & - & - & ○ & - & $\bullet$ & $\bullet$ \\
\hline UK/England+Wales & ○ & $\bullet$ & - & $\bullet$ & O & $\bullet$ & $\bullet$ & $\bullet$ & O & - & ○ & O & $\bullet$ & $\bullet$ \\
\hline UK/Northern Ireland & O & $\bullet$ & $\bullet$ & $\bullet$ & O & $\bullet$ & $\bullet$ & $\bullet$ & $\bullet$ & $\bullet$ & - & $\bullet$ & O & O \\
\hline UK/Scotland & O & • & • & • & $\bullet$ & • & $\bullet$ & $\bullet$ & O & • & O & O & O & - \\
\hline Slovak republic & $\bullet$ & $\bullet$ & - & $\bullet$ & $\bullet$ & $\bullet$ & $\bullet$ & $\bullet$ & $\bullet$ & $\bullet$ & $\bullet$ & $\bullet$ & $\bullet$ & $\bullet$ \\
\hline Slovenia & $\bullet$ & - & - & $\bullet$ & $\bullet$ & $\bullet$ & - & $\bullet$ & - & - & ○ & - & $\bullet$ & - \\
\hline Spain & $\bullet$ & $\bullet$ & - & $\bullet$ & $\bullet$ & $\bullet$ & $\bullet$ & $\bullet$ & O & O & $\bullet$ & ○ & $\bullet$ & - \\
\hline Sweden & $\bullet$ & O & - & $\bullet$ & $\bullet$ & $\bullet$ & $\bullet$ & $\bullet$ & $\bullet$ & - & $\bullet$ & $\bullet$ & $O$ & - \\
\hline Switzerland & • & $\bullet$ & $\bullet$ & $\bullet$ & $\bullet$ & O & $\bullet$ & $\bullet$ & $\bullet$ & $\bullet$ & - & O & O & - \\
\hline Tajikistan & O & $\square$ & - & O & $\bullet$ & $\bullet$ & $\bullet$ & $\bullet$ & $\bullet$ & - & $\bullet$ & $\bullet$ & $\bullet$ & $\bullet$ \\
\hline Turkmenistan & - & $\bullet$ & - & - & $\bullet$ & $\bullet$ & - & $\bullet$ & • & - & - & - & $\bullet$ & O \\
\hline Ukraine & $\bullet$ & ○ & ○ & $\bullet$ & $\bullet$ & - & $\bullet$ & $\bullet$ & O & $\bullet$ & - & ○ & $O$ & - \\
\hline Yugoslavia & $\mathrm{O}$ & O & - & $\bullet$ & $\bullet$ & - & • & $\bullet$ & $\mathrm{O}$ & O & $\bullet$ & ○ & $O$ & 0 \\
\hline
\end{tabular}

๑: yes; ○: no; ๑: incomplete information. Case def: case definition existing; Mand: reporting mandatory; Nom: report includes patient's name; MD: reported by physician; Lab: reported by laboratory; Date: date of diagnosis collected on each patient; Age: age of patient collected on each patient; Sex: gender of patient collected on each patient; Country: country of birth collected on each patient; Site: site of disease collected on each patient; Bact: bacteriological status collected on each patient; Hist: history of previous treatent collected on each patient; Loc: information collected on local level; Reg: information collected on regional level; Nat: information collected on national level. 
smear-positive. Such cases may still qualify as "definite" or "other than definite" cases depending on culture results and other criteria.

\section{Data collection}

Data on individual tuberculosis cases should be collected at local level and they should be made accessible on an ongoing basis to national government authorities. Most countries in Europe have legal provisions for mandatory reporting by physicians. Nevertheless, busy physicians may forget, or otherwise neglect, to report cases of tuberculosis [8], and the legal requirement to report cannot usually be enforced. A few countries have gained experience by additionally requesting level II laboratories (capable of identification of $M$. tuberculosis complex, [7]) to report each isolate of $M$. tuberculosis complex. There are fewer such laboratories than there are physicians potentially seeing cases, making direct involvement of the laboratories with the work of the public health authorities more feasible. Cases reported by laboratories can be followed up with physicians to obtain the required demographic characteristics of the patient and relevant disease-specific information. The Working Group, thus, recommends that national health authorities make both physicians and laboratories subject to mandatory reporting of tuberculosis. Provisions must be made to eliminate duplicate reports and account for subsequent changed diagnoses.

Surveillance may also be strengthened by the provision of information from pharmacies on prescriptions of antituberculosis drugs, as for example in Norway [9].

\section{Timeliness and flow of reporting}

Like other infectious diseases, cases of tuberculosis should be reported promptly after identification. Although annual summary reports of tuberculosis will usually suffice to indicate major changes in the epidemiology of tuberculosis, preliminary national statistics should be published at least quarterly. In the United States, it was the continuous assessment of weekly reports which showed, in September 1985, an unprecedented failure of tuberculosis to decline. This permitted the publication of a warning about the re-emergence of tuberculosis in the United States [10].

\section{Local/regional level}

All patients started on antituberculosis medication should be notified by their physician to the local health authority within 1 week. For this initial report, information on full name, birth date and gender of the patient, presumptive diagnosis, date of starting treatment, and name and address of the reporting physician suffices to ensure that contact tracing in collaboration with the physician is properly initiated where indicated. In countries which have established a continuous reporting system, local health authorities should forward the information to the national authorities, with or without name, depending on the country's legal requirements.
Local health authorities should seek further information from the physician reporting the case, often by means of an extended reporting form (an example of such a form is shown in the Appendix). This information should be returned to the local health authority within a maximum of 3 months following report of a suspect, providing sufficient time to definitively classify a suspect as a notifiable case of tuberculosis.

Laboratories identifying $M$. tuberculosis complex should, simultaneously with their report to the physician requesting the examination, provide information on the bacteriological findings to the local health authority, together with name and address of the physician, full name, birth date and gender of the patient, to permit them to classify definitively a case reported by the physician or to follow-up with the physician concerned on a case hitherto not reported.

\section{From local/regional to national level}

The unit of reporting is the local/regional health authority, which will mostly be found at the district/regional (provincial) level. Local health authorities are responsible for keeping track of suspect cases. Depending on resources and expertise available, local health authorities have the responsibility for collecting information and definitively classifying cases, including linking information from different sources (laboratories, physicians), completing missing information and eliminating duplicate reporting as far as possible. They should forward individual (nonaggregate) information to the national authorities, with or without name or other identifier, depending on the country's legal requirements. This information can be sent to the national authorities on an ongoing basis, or at least quarterly. In the absence of sufficient resources at the local level, nominal (or suitably coded) data would have to be forwarded to the national health authorities to exclude duplications and allow the classification of cases.

\section{National level}

Data from the local/regional level should be aggregated at least quarterly for publication of preliminary statistics. At the national level, final annual summary reports by calendar year will usually be sufficient. Ideally, analysis should be carried out by year of starting treatment, provided the calendar year is closed at the end of the first quarter in the subsequent year, to allow sufficient time for verifying the cases.

A summary of the flow for reporting tuberculosis suspects and cases is provided in figure 1.

\section{Essential variables}

Essential variables include: information characterizing the case by time, place and person, as well as details of site of disease, bacteriological status and whether the patient was previously treated. An example of a reporting 


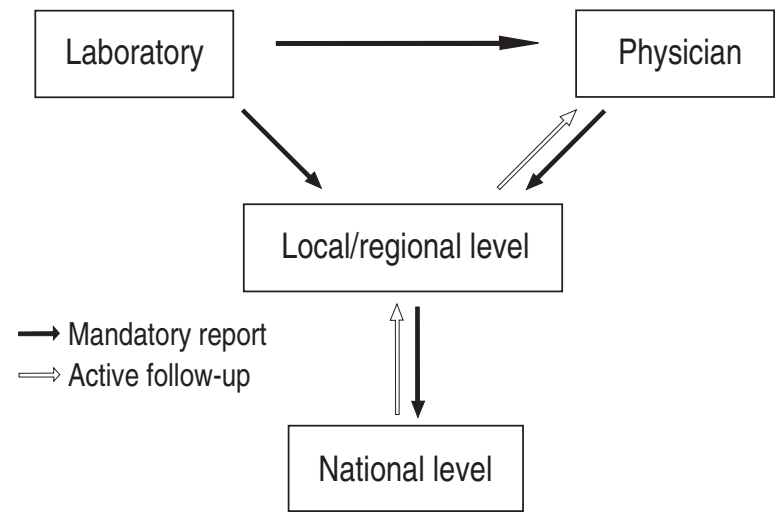

Fig. 1. - Recommended flow chart for reporting a tuberculosis case to local and national level.

form providing the minimal information that is requested from each European country is shown in the Appendix. These variables are described and discussed in the following paragraphs.

\section{Time}

Date of starting treatment. Ideally, to obtain accurate estimates of incidence, the date of onset of disease should be known, but this is not usually practical. Diagnosis is the next obvious date but this may often be difficult to fix in time, so it is recommended that the "date of starting treatment" for tuberculosis constitutes a reasonable proxy and this should be recorded in all cases. The date of starting treatment is defined as the date when the physician is sufficiently confident of his diagnosis to initiate appropriate treatment for tuberculosis. For pulmonary tuberculosis, this will usually be the time when a positive sputum smear result is obtained from the laboratory or, in sputum smear-negative cases, when the clinician has gathered sufficient clinical and/or radiological evidence for the diagnosis to justify starting treatment. When the date of starting treatment is unavailable, the date of notification of the case may be substituted. For cases never receiving treatment, for example postmortem diagnoses, the date of diagnosis should be substituted.

\section{Place}

Place of residence. The "place of residence" of a tuberculosis patient is essential for public health action, and also provides at the national level after appropriate aggregation (by county or region/province) information on differences in disease frequency in different areas of the country. The place of residence should be where the patient was living at the time treatment was started. In cases of homeless people, migrants and detainees, the place of residence within the country during the previous 3 months might be used, or any other solution might be sought as appropriate for individual countries. For European comparison, aggregation by country will usually suffice.

\section{Person}

Age, gender and country of birth. Date of birth to allow the calculation of age at the time of starting treatment and gender are variables that should be known for each patient.

In culturally heterogeneous societies, tuberculosis incidence may vary greatly in different ethnic groups. In view of the increasing importance of tuberculosis in European countries among immigrants and other foreigners, the Task Force on Tuberculosis Control and International Migration identified country of birth as an additional variable that should be collected routinely [5]. In some countries, ethnicity, citizenship, or citizenship of parents may be of more importance than country of birth in characterizing the demographics of tuberculosis patients.

\section{Disease-specific variables}

Site of disease. Site of disease should be recorded in all patients. Because patients may have multiple sites of disease, it is recommended that at least two sites, a major and a minor site, when applicable, be recorded. Because disease site classification may differ in different countries, the following sites are recommended for use, because they will allow further aggregation as needed in a particular country:

Pulmonary. Pulmonary is defined as tuberculosis of the lung parenchyma and the tracheobronchial tree only. It is proposed that pulmonary tuberculosis, if present, should always be listed as the major site, whatever other site may additionally be affected. Extrapulmonary tuberculosis is then defined as tuberculosis affecting any site other than pulmonary as defined.

Pleural. Pleural tuberculosis is defined here as extrapulmonary tuberculosis and is tuberculous pleurisy only, with or without effusion.

Lymphatic. Lymphatic tuberculosis includes tuberculosis involving the lymphatic system. Because of the intrathoracic manifestations of tuberculosis in children and patients with human immunodeficiency virus (HIV) infection, lymphatic tuberculosis is preferably further differentiated into intrathoracic and extrathoracic lymphatic tuberculosis: 1) Intrathoracic - intrathoracic lymphatic tuberculosis; and 2) Extrathoracic - lymphatic tuberculosis other than intrathoracic lymphatic tuberculosis.

It is proposed here that if tuberculosis in children involves both the lung parenchyma and a lymphatic component, the case should be classified as major site pulmonary and minor site intrathoracic lymphatic tuberculosis.

Bone joint. Tuberculosis of the bones and/or joints should be subdivided into: 1) tuberculosis of the spine; and 2) tuberculosis of bones/joints other than spine.

Central nervous system (CNS). Tuberculosis of the central nervous system should be subdivided into: 1) tuberculous meningitis; and 2) tuberculosis of the CNS other than meningitis. 
Genitourinary. Tuberculosis of the genitourinary system, including tuberculosis of kidney, ureter, bladder, and male and female genital tract.

Peritoneal/digestive tract. Peritoneal/digestive tract tuberculosis includes tuberculosis of the peritoneum with or without ascites and tuberculosis of the digestive tract.

Other. Other extrapulmonary sites, including laryngeal tuberculosis, should be aggregated here and, for countryspecific analyses, might specifically be named.

Disseminated. Disseminated tuberculosis includes tuberculosis of more than two organ systems or miliary tuberculosis. If one of the affected sites is the lung parenchyma, the case should be classified as having both pulmonary and disseminated tuberculosis. Miliary tuberculosis, e.g. is thus classified as pulmonary and disseminated. Where $M$. tuberculosis complex has been isolated from blood, the disease site should be designated "disseminated".

To facilitate reporting of disease site in aggregate form at European level, cases should be classified into three groups, i.e. "pulmonary tuberculosis only", "pulmonary and extrapulmonary", and "extrapulmonary tuberculosis only".

Bacteriological status. Information on bacteriological status must always be included. The result of culture (negative or positive for $M$. tuberculosis complex, not done, or pending) and the source specimen must be recorded by the physician and if positive also by the laboratory. Whenever possible, further differentiation of isolates into M. tuberculosis, Mycobacterium bovis, or Mycobacterium africanum should also be reported. Similarly, the result of direct microscopic examination (negative or positive for AFB, or examination not done) must be reported. Histological examination with evidence of AFB should be considered as positive microscopy and recorded accordingly. The specimen from the major site or, if negative or not attempted, from the minor site that provided a positive result should be recorded to clearly classify the case (e.g. sputum smear-positive, culture-confirmed pulmonary tuberculosis or biopsy smear-negative, cultureconfirmed lymphatic tuberculosis). Cases with pulmonary tuberculosis should be reported when aggregating the data as "sputum smear-positive" and "culture-only positive" cases.

Recurrent or new disease. Before starting treatment for tuberculosis it is important to establish: 1) that the patient has active tuberculosis; 2) whether the patient has previously had tuberculosis; and, if so, 3) what treatment for tuberculosis has previously been given. The first two questions are of both epidemiological and clinical concern and the third question is of clinical relevance, since the answer to it will determine the most appropriate treatment of the present episode of tuberculosis.

For public health purposes, it is essential to report all cases of tuberculosis which are diagnosed by physicians. For epidemiological purposes where trends in incidence are of special interest, it must be made clear whether a notified case has or has not had previous tuberculosis. Care must be taken to ensure that chronic cases and intermittently absconding and returning patients are not repeatedly notified. The answer to the following questions should resolve these issues: The first question asks whether the patient has ever had tuberculosis diagnosed before. If the answer is yes, the second question seeks the year of the previous episode, and, if available, the month. A third question determines whether the patient has had previous chemotherapy and, if the answer is yes, whether it was considered adequate or not. This will allow classification of such cases into relapse and recurrence with or without previous chemotherapy and so improve the definition of cases.

\section{Other variables}

Other variables may be collected for specific analyses. Experience shows that information on individual cases is usually more complete the fewer the variables that are requested. The information that is recommended for routine collection as outlined above should be $95 \%$ or more complete for each individual variable. Information which is substantially incomplete is of limited value. For example, information derived from only $60 \%$ of patients may not be representative of all tuberculosis patients.

To increase the specificity of the case definition of other than definite cases, information on tuberculin skin test results in cases without culture confirmation and information on results of chest radiographs may be appended [11].

In countries experiencing a considerable problem of tuberculosis among those with a country of birth other than the current country of residence, a further subdivision by legal status, i.e. by citizenship, and among foreigners grouping into migrant workers, refugees/asylum seekers, and other foreigners may further help to better characterize patients. Duration of residence within the country for foreign-born patients might also be useful information. Not required at the international level, but potentially useful for national assessment, is an ascertainment of the number of cases in which the diagnosis was not made until after death.

Specifically designed surveys should be used to answer more complex questions; physicians are only likely to collaborate and provide the requested information if it is simple, concise, and of immediate obvious general interest. Such surveys may be designed to gather information on prevalence of alcohol and drug-dependence, homelessness, and other variables of special interest in tuberculosis control.

\section{Analysis and reporting}

Public health authorities owe it to reporting laboratories and physicians to regularly analyse, interpret, and publish collected surveillance data. In the case of tuberculosis, such reports should be published on an annual basis. Data should be analysed by calendar year, based on the date the physician reported commencement of 
treatment or, in the absence of such information, the date the case was first notified at local level.

In conclusion, this document represents a consensus of technical recommendations to European Governments on how to structure their tuberculosis surveillance systems with a view to standardization, which would allow international comparisons in Europe. The interpretation of standardized surveillance figures must include an appreciation of the data quality from individual countries.

The majority of European countries responding to the questionnaire collect all information considered essential for surveillance in this report to allow uniform reporting of tuberculosis cases at a European level. Most systems currently in place will, thus, need only minor modifications to allow collation at the European level.

The members of the Working Group, the World Health Organization, and the European Region of the International Union Against Tuberculosis and Lung Disease consider it essential to obtain regular surveillance data on tuberculosis from national governments, to make international comparative analyses of these data, and to distribute them to participating member states. It is only by doing so that changes in trends or patient characteristics nationally or internationally can be detected at an early stage.

\section{Members of the Working Group of the WHO and IUALTD}

J. Martinez Benazet, O. Ramis-Juan (Andorra); M. Safarian (Armenia); J.P. Klein (Austria); F.M. Abdullayev (Azerbaijan); J. Prignot, M. Uydebrouck, P. Vermeire, J-M. Verstraeten, M. Wanlin (Belgium); D. Zehra (Bosnia \& Herzegovina); P. Minchev (Bulgaria); I. Gjenero Margan, R. Pardon (Croatia); D. Dankova, L. Trnka (Czech Republic); G. Pallisgaard (Denmark); E. Tala, K. Liippo, J. Eskola (Finland); C. Moyse, V. Schwoebel (France); M. Forssbohm (Germany); N.E. Yatromanolakis (Greece); D. Kozma, I. Vadász (Hungary); T. Blöndall (Iceland); L. Clancy, P. Kelly (Ireland); D. Chemtob, D. Weiler (Israel); G.B. Migliori, M.L. Moro (Italy); A.D. Djunusbekov (Kazakhstan); R. Zalesky (Latvia); G. Molitor (Luxembourg); H. Agius-Muscat, A. Galea Baron (Malta); D.O. Sain (Moldova); J. Veen, N.A. Kalisvaart (The Netherlands); K. Bjartveit, E. Heldal (Norway); J. Leowski (Poland); M.L. Antunes (Portugal); E. Corlan (Romania); A.G. Khomenko (Russia); A. Bajan, J. Trenkler (Slovak Republic); J. Sorli (Slovenia); J. Alcaide (Spain); V. Romanus (Sweden); J-P. Zellweger (Switzerland); J. Leese,
A.G. Leitch, J. Watson (United Kingdom); O. Djuric, V. Vučuinić (Yugoslavia); H.L. Rieder, International Union Against Tuberculosis and Lung Disease (France); P. Chaulet, M.C. Raviglione, World Health Organization (Switzerland).

\section{References}

1. Thacker SB, Stroup DF. Future directions for comprehensive public health surveillance and health information systems in the United States. Am J Epidemiol 1994; 140: 383-397.

2. Clancy L, Rieder HL, Enarson DA, Spinaci S. Tuberculosis elimination in the countries of Europe and other industrialized countries. Based on a workshop held at Wolfheze, Netherlands, 4-9 March 1990, under the joint auspices of the IUATLD (Europe region) and WHO. Eur Respir J 1991; 4: 1288-1296.

3. Raviglione MC, Sudre P, Rieder HL, Spinaci S, Kochi A. Secular trends of tuberculosis in Western Europe. Bull WHO 1993; 71: 297-306.

4. Raviglione MC, Rieder HL, Styblo K, Khomenko AG, Esteves K, Kochi A. Tuberculosis trends in eastern Europe and the former USSR. Tuber Lung Dis 1991; 75: 400-416.

5. Rieder HL, Zellweger JP, Raviglione MC, Keizer ST, Migliori GB. Tuberculosis control and international migration in Europe. Eur Respir J 1994; 7: 1545-1553.

6. Desenclos JC, Bijkerk H, Huisman J. Variations in national infectious disease surveillance in Europe. Lancet 1993; 341: 1003-1006.

7. Kubica GP, Gross WM, Hawkins JE, Sommers HM, Vestal AL, Wayne LG. Laboratory services for mycobacterial disease. Am Rev Respir Dis 1975; 112: 773-787.

8. Sheldon CD, King K, Cock H, Wilkinson P, Barnes NC. Notifications of tuberculosis: how many cases are never reported? Thorax 1992; 47: 1015-1018.

9. Norwegian Government. Forskrifler om godtgjørelse av utgifter til viktigere legemidler (Regulations on refund of expenses for important drugs). Ministry of Social Affaires, Oslo, 19 December 1984, based on the law on social security, passed 17 June 1966, § 2-5, No. 3, letter a.

10. Centers for Disease Control. Tuberculosis - United States, first 39 weeks, 1985. MMWR 1985; 34: 625-627.

11. Centers for Disease Control. Case definitions for public health surveillance. MMWR 1990; 39: No. RR-13. 
Appendix

\section{Minimum Information on a Tuberculosis Case Reporting Form}

Name and address of patient:

To preserve confidentiality this upper portion may be forwarded in coded form only to national health authorities

Name and address of reporting physician:

(use stamp or print)

Telephone number of reporting physician:

Postal code of patient's residence:

Date of birth (DD/MM/YYYY): I I

Gender: $\square$ male female

Country of birth:

Major site of disease (tick one only):

$\square$ pulmonary

$\square$ lymphatic, extrathoracic

$\square$ CNS, meningeal

disseminated

$$
\square \text { pleural }
$$

$\square$ bone/joint, spine

$\square$ CNS, other than meningeal

peritoneal/digestive tract

Minor site of disease (tick one only):

\section{pleural}

lymphatic, extrathoracic

CNS, meningeal

disseminated

\section{bone/joint, spine}

CNS, other than meningeal

peritoneal/digestive tract lymphatic, intrathoracic

bone/joint, other than spine

genitourinary

other (specify):

lymphatic, intrathoracic

bone/joint, other than spine

genitourinary

other (specify):
Result of direct microscopy:
Specimen:
$\square$ positive $\square$ negative $\square$ not done
Result of culture:
Specimen:
$\square$ positive $\square$ negative $\square$ not done $\square$ pending
Species identification:
M. tuberculosis
M. bovis
M. africanum
$\square$ M. tuberculosis complex
Previous tuberculosis diagnosis: $\square$ yes $\square$ no If yes, month: year:
If a previous case, was previous episode treated with chemotherapy? $\square$ yes $\square$ no $\square$ incomplete information
If yes, was previous chemotherapy adequate? $\quad \square$ yes $\square$ no $\square$ incomplete information

Date treatment was started (or date of diagnosis for patients never receiving treatment for current episode)

(DD/MM/YYYY):

Initial treatment for current diagnosis with:

pyrazinamide

(tick all applicable fields)

$\square$ ethambutol $\square$ streptomycin

other antituberculosis drug

Example form for reporting tuberculosis cases with a minimum set of variables required for uniform case reporting in Europe. 